\title{
Distribución funcional de la renta y capacidad negociadora de los trabajadores en España
}

\author{
Luis Cárdenas \\ Daniel Herrero \\ Universidad Complutense de Madrid e Instituto Complutense de Estudios Internacionales \\ (ICEI) \\ luiscard@ucm.es; d.herrero@ucm.es
}

\section{Resumen}

Este trabajo investiga las razones de la caída continuada de la participación de los salarios en la renta de la economía española durante el período 1987-2015. El análisis toma como variable explicativa fundamental los factores socioinstitucionales que influyen decisivamente en la capacidad de los trabajadores para negociar sus salarios. Identificamos dos grandes ámbitos en los que se han producido importantes transformaciones: el sistema de relaciones laborales y la estructura y regulación del empleo. Primero, empleamos una metodología estadístico-descriptiva para dar cuenta de la relevancia y evolución de ambos. En segundo lugar, elaboramos un índice de capacidad negociadora (ICN) de los trabajadores a partir de siete variables. Nuestras estimaciones indican que el ICN es capaz de explicar gran parte del retroceso de la cuota salarial y que la capacidad de negociación es un determinante fundamental de la distribución funcional de la renta.

Palabras clave: salarios; distribución de la renta; relaciones laborales; España

\section{Abstract. Income distribution and worker's bargaining power in Spain}

The article investigates the main causes that led to the continuous decline of the wage share in the Spanish economy during the period 1987-2015. The analysis takes as the driving factor of the process the evolution of the socio-institutional conditions, which have had a determinant influence on workers' bargaining power. We identify two main areas that have suffered important transformations: the industrial relations system and the labour market. First, we use a descriptive methodology to show the relevance and evolution of both areas. Second, we build a workers' bargaining ability index on the basis of seven variables. Our estimations indicate that the index explains the most of the drop in the wage share and that bargaining power is a critical variable to explain income distribution trends.

Keywords: wages; income distribution; industrial relations; Spain 


\section{Sumario}

1. Introducción 4. Índice de capacidad negociadora

2. La distribución de la renta y sus determinantes durante el período

$1987-2015$

3. El caso español: evidencia descriptiva de los determinantes de la cuota salarial
(ICN): una medida de fortaleza de los trabajadores

5. Relación entre el ICN y la cuota salarial

6. Conclusiones

Agradecimientos y financiación recibida

Referencias bibliográficas

\section{Introducción}

Uno de los aspectos más relevantes de la dinámica socioeconómica en los últimos 30 años ha sido el cambio en la distribución funcional de la renta registrado en la mayor parte de las economías avanzadas (Lavoie y Stockhammer, 2013; Stockhammer, 2017). Este fenómeno, que ha despertado gran interés en la literatura internacional, ha consistido en el aumento de la participación de la rentas del capital en la renta nacional, en contra de las rentas del trabajo (especialmente los salarios). Las causas identificadas han sido múltiples: el progreso técnico (Acemoglu, 2003), la globalización de los flujos comerciales y financieros (Jayadev, 2007), la llamada financiarización (Dünhaupt, 2016) o el deterioro institucional de los mercados de trabajo y estados de bienestar (Kristal, 2010). Estas razones, a excepción de la que alude al progreso técnico (principal argumento de la economía neoclásica), remiten, en última instancia, a una alteración de las posiciones de partida entre trabajo y capital en la pugna distributiva, que ha desembocado en una pérdida de capacidad de negociar salarios por parte del primero.

España no ha permanecido al margen de esta tendencia (CES, 2013), que se ha producido a lo largo de dos períodos económicos muy diferentes. El primero de ellos comprende veinte años, de 1987 a 2007, y, al margen de la breve crisis de 1992 y 1993, se caracterizó por presentar altas tasas de crecimiento económico y un alto incremento de la población ocupada, junto con un fuerte descenso de la tasa de desempleo. El segundo período se extiende de 2008 a 2015, y viene marcado por una profunda crisis económica, especialmente dura entre los años 2011 y 2013, cuando la tasa de desempleo supera el $26 \%$.

El objetivo de este trabajo es conocer las razones de este cambio distributivo de largo plazo en la economía española. Nuestro enfoque se fundamenta en las bases teóricas que han proporcionado varios trabajos que enfatizan la relevancia de los factores socioinstitucionales, sobre los que, a su vez, inciden otros elementos de diversa índole, como son las transformaciones tecnoproductivas. Estos determinantes son agrupados en dos conjuntos de variables:

- Las características de la estructura y la regulación del empleo, en particular, la política laboral y los flujos de entrada y salida de ocupados, que 
determinan el grado de subutilización del trabajo, así como el grado de parcialidad involuntaria, temporalidad y rotación en el puesto de trabajo, y a la vez todo ello determina: (i) el efecto disciplinario del desempleo; (ii) las características de los puestos laborales ofertados y el peso relativo del empleo atípico, y (iii) el grado de protección social del empleo, el nivel de compensación por desempleo y las prestaciones sociales.

- Las características del sistema de relaciones laborales, esto es, los marcos de negociación colectiva y los pactos sociales para mejoras retributivas, que se concretan en: (i) el contenido la de los acuerdos laborales y su nivel o alcance geográfico y/o sectorial; (ii) la capacidad organizativa y reivindicativa de los asalariados.

Estos elementos tienen una influencia decisiva sobre la capacidad de los trabajadores de negociar sus salarios, lo que condiciona el resultado de la pugna distributiva. Con el propósito de recoger su influencia, construimos a partir de las variables mencionadas un índice de capacidad negociadora de los trabajadores (ICN) que nos permite medir cuantitativamente la evolución de su fortaleza en la determinación salarial. El ICN se basa en un método de ponderación «equal weighting», empleado por OCDE (2008) o Eurofound (2018).

Los resultados muestran que es posible explicar la evolución de la cuota salarial mediante este índice. Para ello, se cuantifica la contribución del ICN al descenso de la cuota laboral mediante una regresión lineal con un modelo dinámico, en la cual se incluyen variables de control que capturan otros efectos habitualmente señalados por la literatura. En este sentido, el caso de España es paradigmático y supone un objeto de estudio relevante para la literatura especializada, ya que refleja bien esas transformaciones, como se expone más adelante.

El documento se estructura como sigue. ${ }^{1}$ En el apartado 2, se muestra la evolución de la participación salarial en España y otras economías avanzadas, y se presentan brevemente las principales causas esgrimidas por la literatura para explicar los cambios en la distribución funcional de la renta. En el punto 3, se exponen las transformaciones acaecidas en los dos grandes ámbitos que conforman el poder de los trabajadores: las condiciones de empleo y el sistema de relaciones laborales. En la sección 4, se expone la metodología de elaboración del ICN, y en el punto 5 se realizan un conjunto de estimaciones para probar su capacidad explicativa. Finalmente, el último punto se dedica a las conclusiones obtenidas.

\section{La distribución de la renta y sus determinantes durante el período 1987-2015}

\subsection{La evolución de la participación salarial}

La evolución de la cuota salarial, por definición, es directamente dependiente del comportamiento del salario por hora nominal, de los precios y de la pro-

1. Una versión preliminar de este artículo fue publicada en la serie ICEI Working Papers (Cárdenas del Rey y Herrero Alba, 2018). 
Figura 1. Evolución de la participación salarial ajustada en 13 economías avanzadas (19872015)

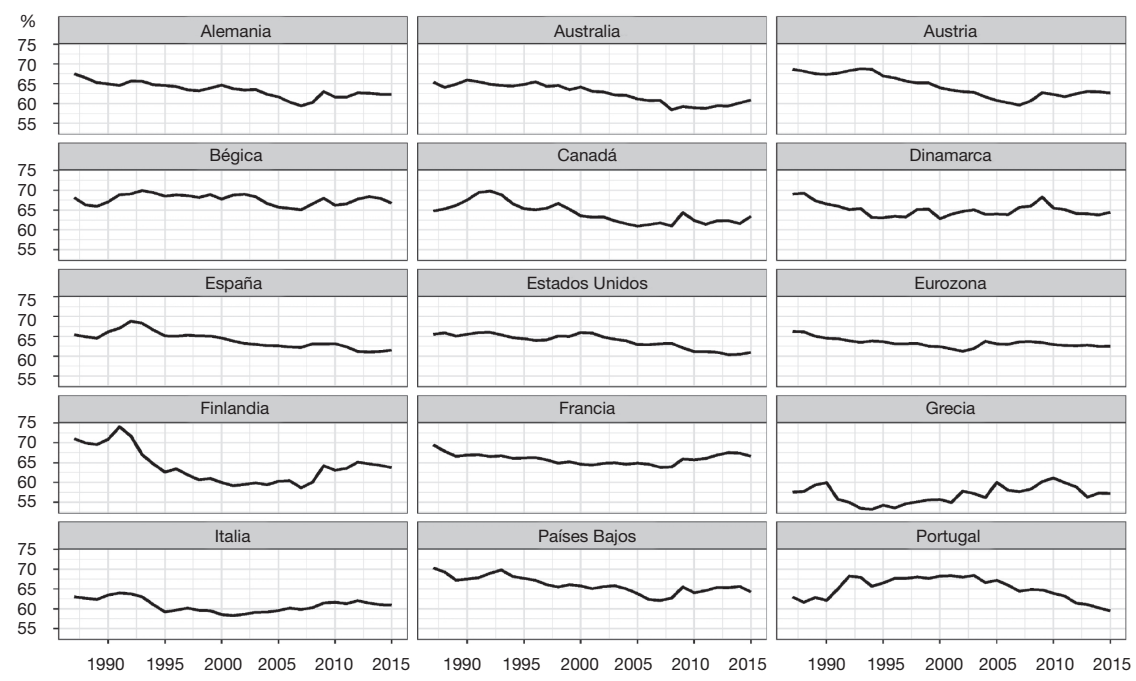

Fuente: AMECO (Annual Macro-economic Database of the European Commission).

ductividad real por hora. Por ello, si el salario nominal crece al ritmo de los precios y la productividad real, los trabajadores mantendrán su poder adquisitivo. El cambio distributivo se dará a favor de la cuota salarial si el salario nominal crece más que los precios y la productividad; si crece por debajo, este se producirá a favor de las rentas del capital.

La caída de la participación salarial no es un fenómeno particular de España. Al contrario, se trata de una tendencia de largo plazo común a las economías avanzadas (Stockhammer, 2017). En los quince países de la figura 1, su descenso ha sido de 4,0 puntos porcentuales (pp) como promedio, si bien este ha sido más pronunciado y continuado en algunas economías que en otras. Durante nuestro período de estudio, 1987-2015, las mayores caídas se han dado en los Países Bajos (7,5 pp) y en Italia (6,3 pp).

En el caso español, la caída acumulada de la cuota salarial ha sido de 4,1 pp, consecuencia de un crecimiento de la productividad del 37,4 \% y del 27,6\% del salario por hora. La ratio se mueve del 59,5\% en 1987 al 63,0 \% en 1993, el punto más elevado del período. Desde entonces disminuye 7,3 pp, hasta llegar al 55,5\% en 2015.

Lo característico de la economía española es que esta caída se ha registrado a lo largo de dos etapas económicas radicalmente diferentes. Durante la primera (1987-2007), la cuota salarial descendió 3,5 pp. En esta etapa se registró un notable crecimiento de la demanda agregada (3,3\% anual), liderado por el comportamiento de la inversión. Desde el punto de vista de la producción, se 
constata un moderado aumento de la productividad por hora (en esos 20 años se incrementó un $24 \%$ en términos acumulados), a la vez que un crecimiento todavía más débil del salario real, que, si bien crece aceleradamente hasta 1993 (23\%), de 1994 a 2007 retrocede un 6,5\% (figura 3, página 10).

A lo largo de la segunda etapa, en el intervalo de crisis 2008-2015, la cuota salarial se contrajo $2,5 \mathrm{pp}$, pero por razones diferentes. El salario medio real ${ }^{2}$ por hora crece, pero lo hace por la elevadísima destrucción de empleo, muy superior a la de la masa salarial. La productividad creció mucho por la misma razón: la caída del empleo y el incremento de la intensidad laboral. En ambos casos opera el efecto composición, esto es, un menor crecimiento de la productividad del trabajo, como consecuencia de la caída de la demanda, que del salario medio, el cual incluso aumenta porque los primeros en ser expulsados de sus ocupaciones fueron los trabajadores de bajos salarios y con peores condiciones de trabajo. A partir de 2014, cuando se reanuda el crecimiento, tanto el salario medio como la productividad vuelven a estancarse.

\subsection{Principales explicaciones de la caída de la cuota salarial}

Desde las ciencias sociales se han ofrecido diversas explicaciones a la reducción de la participación de los salarios en la renta. La economía neoclásica ha señalado al progreso técnico como la principal variable explicativa. Este tiene un impacto diferenciado sobre el empleo y la dispersión salarial según la cualificación de los trabajadores (skill-biased technological change) o el nivel de rutina del puesto de trabajo (routine-biased technological change). Los procesos de digitalización y automatización son, según la primera tesis, complementarios a las habilidades de los trabajadores más cualificados y sustitutivos de los que lo son menos (Card y DiNardo, 2002), lo que afecta a su demanda relativa y a los salarios. La segunda tesis defiende que las nuevas tecnologías son sustitutivas de las ocupaciones rutinarias (que suelen ser las de cualificación intermedia), de manera que su efecto es negativo sobre salarios y empleo. Por el contrario, son complementarias a las tareas de mayor cualificación (las más abstractas y difícilmente reemplazables por máquinas) y relazan su productividad, demanda relativa y salarios. Su efecto sobre las de menor cualificación es dudoso: aunque son tareas difícilmente sustituibles, tampoco son complementarias a las nuevas tecnologías (Autor, 2015). El resultado de ambas tesis es la polarización de la estructura salarial, pero esto también repercute sobre la cuota laboral porque, en términos agregados, estas tecnologías favorecen la productividad del capital, que crece por encima de la del trabajo y, con ello,

2. Al analizar la distribución funcional de la renta, se estudian los costes laborales unitarios en términos reales (CLUR), de esta forma se descuenta al crecimiento de los salarios y de la productividad en términos nominales la evolución de los precios. Los costes laborales unitarios (CLU) relacionan la evolución del salario nominal con la productividad real. En la medida en que los precios aumentan más que los CLU, el peso de las rentas del capital aumentará, mientras que si los CLU crecen más que los precios se está produciendo un incremento del porcentaje de las rentas del trabajo sobre la renta nacional. 
su remuneración (capital-biased technological change) (Acemoglu, 2003). En definitiva, para la economía neoclásica no hay cambios en la capacidad negociadora, sino alteraciones en las productividades marginales de los factores productivos.

Por otra parte, desde la economía política internacional, se ha apuntado a la globalización comercial y financiera como principales determinantes de la distribución de la renta. Concretamente, el aumento de la movilidad de los factores productivos altera las posiciones negociadoras del trabajo y el capital, que son crecientemente favorables al segundo, que es el más móvil. De esta manera, la apertura comercial y el aumento de los flujos de IED afectan negativamente a la cuota salarial porque obligan a competir entre sí a trabajadores de distintos países. Los salarios de los sectores de bienes y servicios transables se ven presionados a la baja por la competencia internacional y, a la vez, la inversión tiende a moverse hacia regiones donde los costes laborales son menores, con el resultado de un descenso de la cuota salarial (Rodrick, 1997; Jayadev, 2007; Onaran, 2011).

Relacionado con la globalización financiera, una tercera línea de investigación señala a la financiarización de las empresas como variable explicativa de la cuota salarial (Dünhaupt, 2016). El creciente control corporativo de agentes con objetivos financieros y las rentabilidades que ofrecen estos mercados han desviado la atención de las compañías productivas de sus actividades habituales. La implementación de estrategias que favorecen el incremento del valor accionarial y el reparto de dividendos se erigen sobre los tradicionales objetivos de crecimiento empresarial en el largo plazo. Como resultado, los niveles de actividad económica se reducen por el efecto crowding out de la inversión financiera sobre la productiva, y el conflicto distributivo se intensifica en el interior de las empresas (Stockhammer, 2004).

Nuestro estudio se enmarca en una cuarta línea de investigación que resalta la importancia de las instituciones. La distribución de la renta se entiende como un juego de suma cero, cuyo resultado se decide por las relaciones de poder existentes entre trabajo y capital, que, a su vez, vienen determinadas por factores institucionales. El retroceso de los estados de bienestar (Clayton y Pontusson, 1998), el deterioro de las organizaciones sindicales y la descentralización de la negociación colectiva y la liberalización de los mercados de trabajo (Bengtsson, 2014) han minado la capacidad negociadora de los trabajadores y, con ello, deteriorado la participación salarial. Además, variables presentes en otros enfoques, como el progreso técnico o la globalización, se integran en estos análisis porque inciden sobre los factores socioinstitucionales y, con ello, el poder negociador. El trabajo más representativo de esta perspectiva es el de Kristal (2010), que conceptualiza una noción de poder de los trabajadores sustanciada en tres dimensiones: la capacidad organizativa (que crece con la organización sindical y el conflicto social), la organización en la esfera política (que crece con los gobiernos socialdemócratas y con el aumento del gasto público) y el poder estructural de la clase trabajadora (que disminuye con el aumento de los flujos comerciales, migratorios y financieros). 
Con el objetivo de evaluar empíricamente estas aproximaciones, Stockhammer (2017) recoge variables referentes a todas ellas en un estudio econométrico con un panel de economías avanzadas y en desarrollo. En este trabajo, encuentra evidencia a favor de que la globalización, el deterioro del estado de bienestar y las instituciones laborales y la financiarización han contribuido decisivamente al cambio distributivo. No obstante, el progreso técnico no ha tenido el impacto esperado por la economía neoclásica; al contrario, su impacto ha sido positivo.

\section{El caso español: evidencia descriptiva de los determinantes de la cuota salarial}

Durante el período de estudio, en España se produjo un conjunto de transformaciones socioinstitucionales y de carácter tecnoproductivo en el mercado de trabajo y en el ámbito de las relaciones laborales que contribuyó al deterioro de la capacidad negociadora de los trabajadores. Al mismo tiempo, hubo un importante cambio en la distribución de la renta. Estas transformaciones se dieron en dos etapas económicas muy diferentes y bajo gobiernos de distinto signo, por lo que esta circunstancia constituye un caso de estudio relevante para la literatura especializada.

\subsection{Transformaciones del empleo}

La evolución del empleo en España ha sido tradicionalmente muy sensible al ciclo económico, y su expansión ha estado estructuralmente limitada por la especialización productiva de la economía (Portella-Carbó, 2017). A lo largo del período 1987-2015, su comportamiento fue radicalmente distinto en las fases expansivas (1994-2007) y en las fases de contracción (las crisis de 199293 y 2008-2013).

Durante los años 1987-2007, se produjo un rápido aumento del nivel de ocupación, que obedeció al intenso crecimiento del intervalo de 1994-2007 (EPA, Instituto Nacional de Estadística). En cifras absolutas, el número de ocupados se incrementó en 8,5 millones, de los que 8 millones correspondieron al segundo intervalo. Por su parte, el nivel de desempleo se mantuvo entre el $15 \%$ y el $20 \%$ entre 1987 y 1993. En 1994 descendió del $20 \%$ (3,9 millones de desempleados) y disminuyó hasta el mínimo del 8 \% (2 millones) en 2007, cifra que seguía siendo alta en comparación con otros países de la Unión Europea. Durante la crisis posterior (2008-2013), la pérdida de empleo fue igualmente intensa, ya que alcanzó los 3,3 millones de puestos de trabajo (esto supone el $40 \%$ del empleo creado en 1987-2007), y la tasa de desempleo se disparó y se situó por encima del $26 \%$ en 2013 (más de 6 millones de desempleados), para descender al $22 \%$ en 2015.

Sin embargo, la expansión del empleo se consolidó sobre dos procesos simultáneos que deterioraron el poder negociador de los trabajadores. Primero, la expansión de la ocupación se sostuvo sobre una segmentación crecien- 
te del mercado laboral mediante el surgimiento de una mayor variedad de cualificaciones, categorías y jerarquías laborales (López, 1996; López, et al., 1998; Toharia, 2003; Blanco, 2005; Torrejón, 2019) y una amplia variedad de modalidades de contratación atípicas, que resultaron de múltiples reformas laborales de carácter liberalizador (Sola et al., 2013). Entre estas modalidades, destaca el empleo temporal (alrededor del $33 \%$ de la ocupación), el trabajo a tiempo parcial $(12 \%)$ y los puestos de trabajo considerados como prácticas y en formación (Toharia, 2003; Polavieja, 2005; García-Serrano y Malo, 2013). Asimismo, la incorporación de maquinaria automatizada supuso un cambio en la organización laboral. Esta maquinaria impactó negativamente sobre el empleo de cuello azul (García Calavia, 2001), y acentuó la polarización de la cualificación laboral y de las retribuciones salariales, tanto hacia trabajos de mayor cualificación y salarios como, en el extremo contrario, hacia trabajos de escasa cualificación, bajos salarios y mínimos derechos y garantías contractuales $^{3}$ (García-Serrano y Malo, 2013). Estas figuras atípicas de empleo son las que explican el frenético comportamiento de esta variable: su crecimiento fue acelerado durante la expansión, del mismo modo que sobre ellas se concentraron los fuertes procesos de ajuste en la crisis (Fernández et al., 2016).

En segundo lugar, la economía española se ha especializado en sectores muy intensivos en empleo (Cuadrado y Maroto, 2012), particularmente de servicios (García-Nogueroles, 2010). Durante la etapa de mayor crecimiento, 1994-2007, gran parte de la creación de nuevos puestos de trabajo se sustentó sobre la construcción, los servicios inmobiliarios, los servicios a empresas y el comercio al por menor, todos ellos sectores de baja productividad y poco permeables al progreso técnico. Esto explica la tendencia de España no solo a presentar coeficientes capital-trabajo comparativamente inferiores a los de otras economías avanzadas, sino también a que el crecimiento de esta ratio sea muy lento. Las elevadas tasas de inversión del período se han concentrado en estos sectores y el capital que han formado es poco productivo, lo que resta capacidad de crecimiento potencial a los salarios medios.

En la figura 2 se representa la trayectoria de la relación entre el stock de capital productivo y el número de trabajadores en el conjunto de la economía $(\mathrm{K} / \mathrm{L})$. Se observa que esta ratio aumenta muy lentamente en los períodos de crecimiento económico (1,3\% anual entre 1994 y 2007), y crece aceleradamente durante los años de crisis (en 1992-1993 lo hace al 9,5\% y en 20082013 al 6,8 \%), es decir, solo hay incrementos cuando se destruye empleo y no cuando más crece la inversión.

Este es un factor explicativo clave de la evolución contracíclica de la productividad en España (figura 3). Y es que el patrón de crecimiento español no ha estimulado la inversión en capital productivo que permita aumentos de la productividad, de tal forma que la fuente fundamental del crecimiento

3. De tal forma que los nuevos puestos de trabajo fueron ocupados por contingentes laborales, especialmente mujeres e inmigrantes, que tenían condiciones laborales mucho más precarias (bajos salarios, elevada temporalidad, abundante trabajo a tiempo parcial y elevada rotación). 
Figura 2. Evolución de la ratio $\mathrm{K} / \mathrm{L}$ y del peso del empleo en la manufactura en la economía (1987-2015)

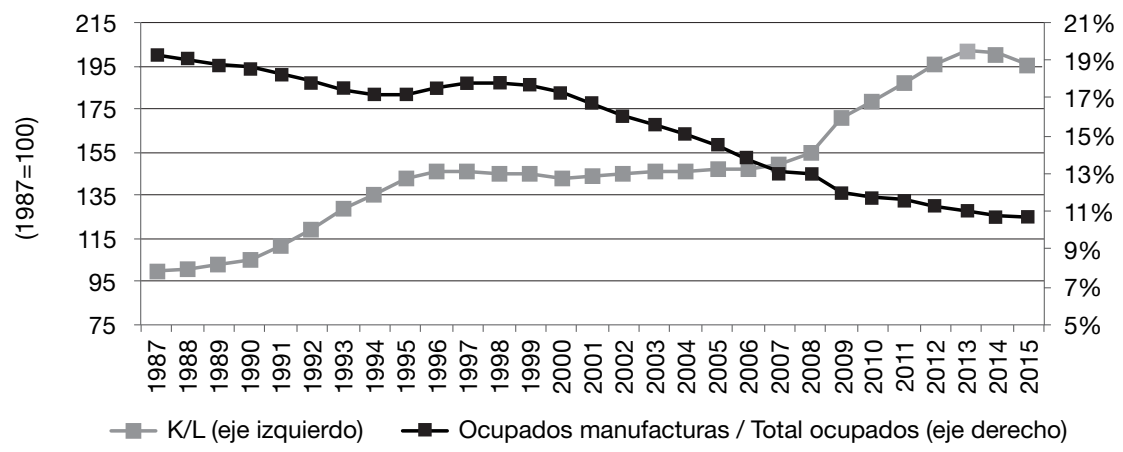

Fuente: elaboración propia a partir de EUKLEMS.

de los beneficios empresariales durante los momentos de auge económico es la contención salarial.

Como consecuencia, se produjo en el período un cambio en la estructura del empleo que, aunque se ha dado en todas las economías avanzadas, en España ha sido más intenso. El peso relativo del empleo del sector manufacturero descendió progresivamente hasta 1998 y velozmente desde ese año hasta 2015 (figura 2). Es de destacar que la manufactura ha sido de los pocos sectores de actividad en los que la participación salarial ha aumentado en el período 19872007 (1,0 \% anual), aunque esta conducta se invierte a partir de la crisis y la cuota salarial disminuye más rápidamente que en el conjunto de la economía, algo llamativo al tratarse del sector en el que existe mayor fortaleza sindical (junto con la Administración pública). Por ello, es necesario profundizar en los cambios que se han producido en las relaciones laborales.

\subsection{Transformaciones en el sistema de relaciones laborales}

En España, los mecanismos de negociación salarial han estado condicionados por una política de rentas consistente en la concertación social competitiva o corporativismo competitivo (Sánchez Mosquera, 2013), según la cual la moderación salarial era condición necesaria para conseguir estabilidad macroeconómica. A esto contribuye el contexto del proceso de integración en la Unión Europea, la formación de la Unión Económica y Monetaria (iniciada en junio de 1988 y consolidada a partir del Tratado de la Unión Europea firmado en Maastricht en 1992) y, tras ella, la firma del Pacto de Estabilidad y Crecimiento (aprobado por el Consejo Europeo en 1997), que buscaba crear las condiciones para la moderación salarial con el objetivo de que las tasas de inflación de los Estados miembros convergieran. En este punto, es posible distinguir tres grandes etapas en la evolución del marco de relaciones laborales (Molina, 2014). 
La primera corresponde a los años ochenta y se extiende hasta mediados de los noventa, cuando los sucesivos gobiernos del PSOE participaron activamente en una negociación salarial tripartita con empresarios y sindicatos. La estrategia de esos gobiernos persistió en los objetivos centrales establecidos desde los Pactos de la Moncloa: prioridad para la estabilidad monetaria (control de la inflación) y el crecimiento de los beneficios empresariales, considerados como condiciones sine qua non para el aumento de la inversión y el empleo, colocando los salarios, el desempleo y la política social como variables subsidiarias del beneficio y de las ventajas otorgadas a las empresas (Etxezarreta, 1991).

Estos objetivos exigían un requisito político-social: el respaldo de los sindicatos a las medidas acordadas en esa línea. Si bien esto se consiguió inicialmente mediante el apoyo de la UGT, las diferencias políticas entre este sindicato y el gobierno del PSOE deterioraron su relación (Astudillo, 2004). El punto de inflexión lo marca la capacidad movilizadora mostrada en la huelga general del 14-D de 1988, una vez conseguida la unidad de acción entre los sindicatos mayoritarios. Esto se tradujo tanto en un incremento de las demandas para un "giro social» en la política económica (se consiguieron pactos entre el gobierno socialista y los sindicatos) como en un importante aumento de los salarios (entre 1988 y 1995 el salario por hora incrementó un $15 \%$, subida superior al crecimiento de la productividad por hora).

La segunda etapa (González y Luque, 2015) se corresponde con el debilitamiento del sistema de concertación social tripartita, en que pasaron a tener un mayor predominio los acuerdos interconfederales, con los cambios introducidos a partir de mediados de los años noventa. Tras la recesión de 1993, la capacidad de los sindicatos para afectar a la política económica se debilitó considerablemente, lo cual se tradujo en una reforma laboral (1994) que dio una mayor flexibilidad al despido, y una modificación en el Estatuto de los Trabajadores (1995) que permitía la inaplicación salarial de convenios de ámbito superior, con el requisito de acuerdo previo entre las partes.

En los gobiernos del Partido Popular, primero se firmó el Acuerdo Interconfederal para la Estabilidad en el Empleo (1997) y, posteriormente, el Acuerdo Interconfederal para la Negociación Colectiva (ANC). El ANC, iniciado en 2002 y sucesivamente prorrogado o renovado hasta el año 2008, establecía como criterio central de determinación salarial la moderación en los incrementos pactados, e incluía como referencia la inflación prevista para ese año, el crecimiento de la productividad para ese año y la cláusula de revisión salarial, con objeto de evitar espirales inflacionistas. En la práctica, el incremento de los abanicos salariales imposibilitó que los acuerdos firmados en los niveles superiores se generalizaran al conjunto de los trabajadores, y el salario real se redujo durante 10 años (entre 1996 y 2007 se contrajo un $24 \%$ ), como se observa en la figura 3.

La tercera etapa comienza en 2010, cuando arranca una nueva ronda de acuerdos interconfederales denominados Acuerdo para el Empleo y la Negociación Colectiva (AENC), con cobertura trianual y donde se establece una importante moderación del crecimiento del salario nominal, ya que en los 
Figura 3. Evolución del salario real y la productividad (1987-2015)

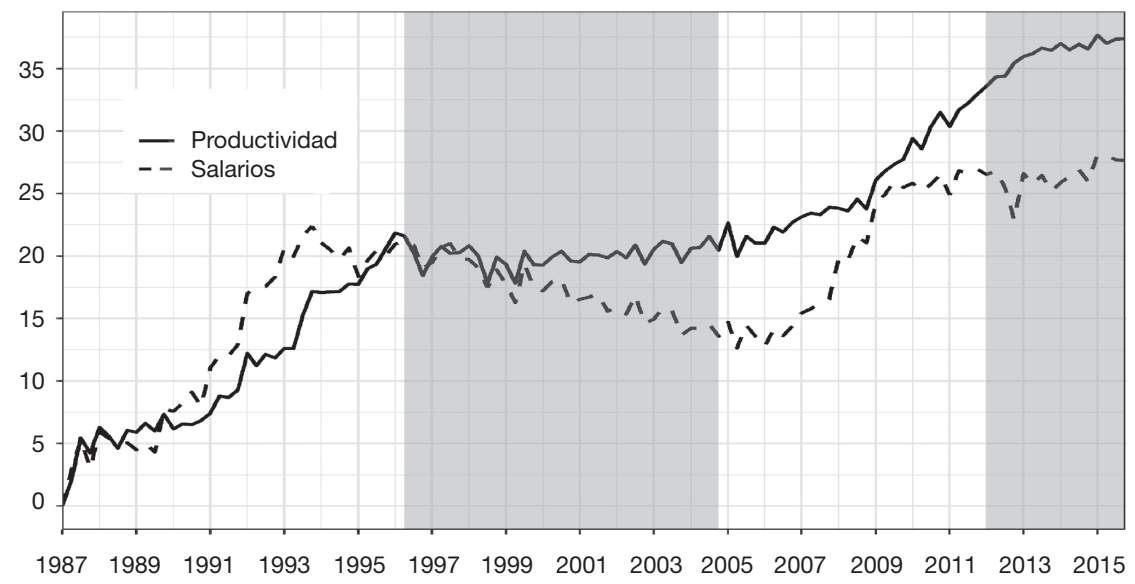

Nota: datos trimestrales. Tasas de crecimiento desde el 1er trimestre de 1987 en porcentaje. Las áreas sombreadas indican gobiernos del Partido Popular y las blancas del PSOE.

Fuente: elaboración propia a partir de la Contabilidad Nacional Trimestral (CNTR).

tres AENC firmados hasta la fecha no se han pactado crecimientos salariales nominales superiores al $2 \%$ (teórico objetivo de inflación), condicionados a la evolución de la economía y/o la situación sectorial y empresarial. Se trata de una política de devaluación salarial que vino acompañada por otras políticas de austeridad fiscal implementadas por los gobiernos del PSOE y el PP.

Sin lugar a dudas, esta etapa ha estado marcada por una significativa descentralización de la negociación colectiva para adaptarla a las necesidades individuales de las empresas. Las reformas laborales de 2010 y, sobre todo, de 2012 transformaron la orientación de la negociación, y los convenios colectivos comenzaron a ser exclusivamente funcionales al desempeño empresarial (Casas, 2014), mediante la introducción de: (i) la posibilidad de inaplicación temporal del convenio colectivo de forma unilateral por el empresario, (ii) la prioridad aplicativa del convenio de empresa, (iii) la posibilidad de renegociación unilateral de un convenio en activo, y (iv) límites a la ultraactividad de los convenios.

En conclusión, a lo largo de todo el período, estos cambios han provocado el debilitamiento de los mecanismos de negociación de los convenios dentro del sistema multinivel que caracteriza el modelo español (Luque, 2012). La firma de acuerdos centralizados e interconfederales entre los sindicatos y las organizaciones patronales no ha sido un obstáculo para que, con el uso de la laxitud de la normativa legal, un número creciente de empresas pudiera aplicar criterios discrecionales sobre salarios y condiciones laborales. De esa manera, fue aumentando el número de asalariados cuyas empresas no se acogían a los convenios o solo aplicaban determinadas cláusulas, de modo que se modificaba el contenido de los acuerdos en la cumbre en las siguientes rondas de negociación sectorial, provincial y empresarial. 
Asimismo, cabe destacar otros factores relevantes en los cambios del sistema de relaciones laborales que se han producido a lo largo de todo el período y que son habitualmente destacados. El primero es el efecto de la terciarización. El fuerte aumento de actividades de servicios cada vez más heterogéneas se ha traducido en una pérdida de importancia de sectores que ofrecían trabajos más uniformes, y tenían una mayor tradición reivindicativa y sindical (Blanco, 2005), con la consiguiente transformación de la cultura de negociación colectiva.

El segundo es que la creciente internacionalización de la producción a través de cadenas que fragmentan los procesos productivos ha debilitado la capacidad negociadora de los trabajadores. Recientemente, se han llegado a firmar acuerdos marco internacionales (AMI) con sindicatos globales y compañías transnacionales como protagonistas. Sin embargo, hasta la fecha, estos acuerdos han tenido como objetivo el cumplimiento de estándares laborales mínimos a lo largo de la cadena de valor, junto con la consecución de ciertos objetivos de responsabilidad social corporativa (Beneyto, 2016).

El tercero es que el proceso de financiarización (Alonso y Fernández-Rodríguez, 2012) y el cambio en la orientación de los objetivos corporativos, al aumento del valor del accionista, han favorecido una individualización de las relaciones laborales, especialmente entre profesionales y técnicos cualificados, y han introducido activos financieros como complementos al salario.

A todo lo anterior, se añade el progresivo debilitamiento sindical en términos organizativos, reivindicativos y negociadores, que ha contribuido a reforzar la segmentación entre los asalariados. También es evidente la tendencia descendente de la afiliación sindical debido al propio marco de relaciones laborales. Su posición negociadora se ha centrado en la defensa del salario y el empleo, pero, a pesar de los intentos de modificación de las políticas laborales para evitar la dualidad contractual (especialmente relevante es el caso de la huelga general de 1988), de facto se ha ahondado la fractura entre los trabajadores cubiertos y aquellos que no estaban amparados por los acuerdos (Rueda, 2014).

Todo ello se ha traducido en que, independiente del partido político que sustentara al Gobierno, el salario real ha crecido menos que la productividad del trabajo desde el giro producido en los primeros años 90. En términos de CLU, esta evolución significa que los precios han crecido más que los CLU y han incrementado el peso de las rentas del capital. En otras palabras, desde entonces, los trabajadores han percibido una proporción cada vez menor de la renta nacional.

\section{4. Índice de capacidad negociadora (ICN): una medida de fortaleza de los trabajadores}

Lo explicado con anterioridad da a entender que el proceso de formación de salarios y la distribución funcional de la renta son resultado de una pugna entre trabajadores y empresarios, cuyas posiciones negociadoras, aunque influenciadas por factores de mercado, están condicionadas por factores socioinstitucio- 
nales. De esta forma, el poder negociador de los trabajadores es una variable determinante para explicar la evolución de los salarios en la renta.

La literatura ha presentado índices que han tratado de medir la capacidad negociadora de los agentes económicos. Desde posiciones estructuralistas norteamericanas (Schor y Bowles, 1987), son conocidos los intentos de medir la pugna distributiva mediante el indicador del coste de perder el empleo (diferencia entre el salario percibido y la duración y la remuneración de la prestación por desempleo). Sin embargo, este tipo de indicadores no trascendieron del contexto de esta escuela y no son directamente trasladables al caso español por las limitaciones estadísticas.

Por otra parte, son más comunes los estudios comparativos acerca de las características y los efectos económicos de las instituciones de regulación del empleo y relaciones laborales. En ellos se utilizan medidas tradicionales de la estructura de la negociación colectiva, como la tasa de cobertura y la afiliación sindical. En ocasiones, se elaboran índices más complejos, como el de concentración sindical de Wallerstein (1999) o los de coordinación de la negociación colectiva (Kenworthy, 2001, ofrece un buen resumen de todos). En esta línea, Visser (2015) ha desarrollado dos índices compuestos para captar de forma precisa el nivel en el que se negocian los salarios (mediante el índice de centralización de la negociación salarial, CWB) y la coordinación de los sindicatos en la negociación (a través del índice Cent). Estas medidas han sido empleadas para llevar a cabo dos tipos de estudios: primero, los trabajos que, en la línea de Calmfors y Driffill (1988), analizan qué tipo de instituciones nacionales de negociación colectiva son las más adecuadas para contener el crecimiento de los salarios y el desempleo (Aidt y Tzannatos, 2008); segundo, el conjunto de estudios que realizan comparaciones internacionales sobre la evolución de estas mismas instituciones, con el objetivo de conocer cómo el proceso de globalización ha actuado sobre ellas (Visser, 2016). Los trabajos de la OCDE (1997; 2004) combinan ambos tipos de perspectivas. También es necesario señalar el índice de protección del empleo que analiza los procedimientos de despido individual o colectivo de manera comparada entre los distintos países de la OCDE. En un punto intermedio entre los estudios estructuralistas y los de economía comparada, se encuentra el índice de capacidad negociadora (ICN), que cuantifica la fortaleza de los trabajadores en la pugna distributiva con el objetivo de explicar el movimiento de la cuota salarial. Tomamos como referencia el índice de poder sindical elaborado por Pérez Ortiz (2004), que incorpora indicadores de fortaleza de los sindicatos que van más allá de la tasa de afiliación sindical y la cobertura de la negociación colectiva, que, aunque son los empleados por la literatura, son insuficientes para dar cuenta de un fenómeno tan complejo y multidimensional. No obstante, incluimos nuevas variables y, como se verá, aplicamos el método de ponderación «equal weighting», también empleado por la OCDE (2008) o Eurofound (2018). De tal forma, el ICN se compone de siete variables, relacionadas con los dos ámbitos socioinstitucionales mencionados: la estructura de la negociación colectiva y las instituciones de mercado de trabajo. A continuación, los describimos. 
Variables de estructura de las relaciones laborales (figuras 4-6): estas variables recogen la fortaleza de los sindicatos y su capacidad de movilización entendiendo que, si crece su poder, también lo hace su capacidad de lograr mejoras salariales. A su vez, se incluye la tasa de cobertura de la negociación colectiva como medida del alcance de los acuerdos salariales.

a) Tasa de afiliación sindical: esta medida capta la fortaleza de los sindicatos teniendo en cuenta la proporción de asalariados que forman parte de alguna organización sindical. Se asume que la fortaleza de los sindicatos como actores relevantes en la negociación colectiva radica, en parte, en su representatividad. Cuanto mayor sea la tasa de afiliación, más amplia será la base social de los sindicatos y, por tanto, su capacidad de movilización y acción colectiva (Olson, 1982; Calmfors y Driffill, 1988). La relación entre la afiliación y la participación salarial es, por lo tanto, positiva, ya que, cuanto mayor sea la primera, mayor será su capacidad de negociación para aumentar salarios o para suavizar las iniciativas de contención salarial.

b) Conflicto laboral: el conflicto laboral afecta a la fijación de salarios, ya que, cuanto mayor sea el primero, más posibilidades tiene la fuerza de trabajo de incrementar salarios o de contener intentos de retroceso salarial (Rubin, 1986; Hibbs, 1987). El conflicto es medido a través de la relación entre la cantidad de participantes en las huelgas y el total de la fuerza de trabajo. Este indicador mide el grado de respuesta de los afiliados al sindicato a las llamadas a la huelga, junto con el grado de aceptación de los objetivos sindicales en el conjunto de la fuerza de trabajo, ya que en España la cobertura de la negociación colectiva trasciende a los miembros del sindicato. A efectos de la construcción del índice, se han utilizado las series de actividad huelguística que incluyen los datos correspondientes a los años en los que se produjeron huelgas generales: 1988 (diciembre), 1992 (mayo), 1994 (enero), 2002 (junio), 2003 (abril) y 2012 (marzo y noviembre).

c) Tasa de cobertura de la negociación colectiva: la cobertura de la negociación colectiva indica la proporción de trabajadores asalariados cubiertos por convenios sectoriales y nacionales. Se trata de una medida de integración de los trabajadores en objetivos comunes o de competición intraclase (Kristal, 2010 - aunque ella emplea un índice de centralización de la negociación colectiva-). En España, rige el principio erga omnes, según el cual lo acordado en un convenio sectorial (nivel predominante en el que se organiza la negociación) se extiende a todos los trabajadores del sector o rama de actividad al que pertenece el sindicato que lo firma, con independencia de que estén afiliados o no a él. Por tanto, los acuerdos a los que son capaces de llegar los sindicatos son más incluyentes (la organización de los trabajadores es mayor, hay menos competitividad entre unidades negociadoras) cuanto mayor sea la tasa de cobertura. Si bien la literatura sostiene que la relación entre ambas variables no es unívoca (Wright, 2000), y aunque el contenido de los convenios está condicionado por el modelo de concertación social competitiva, el incremento salarial pactado ha supuesto 
Figura 4-6. Variables de estructura de las relaciones laborales
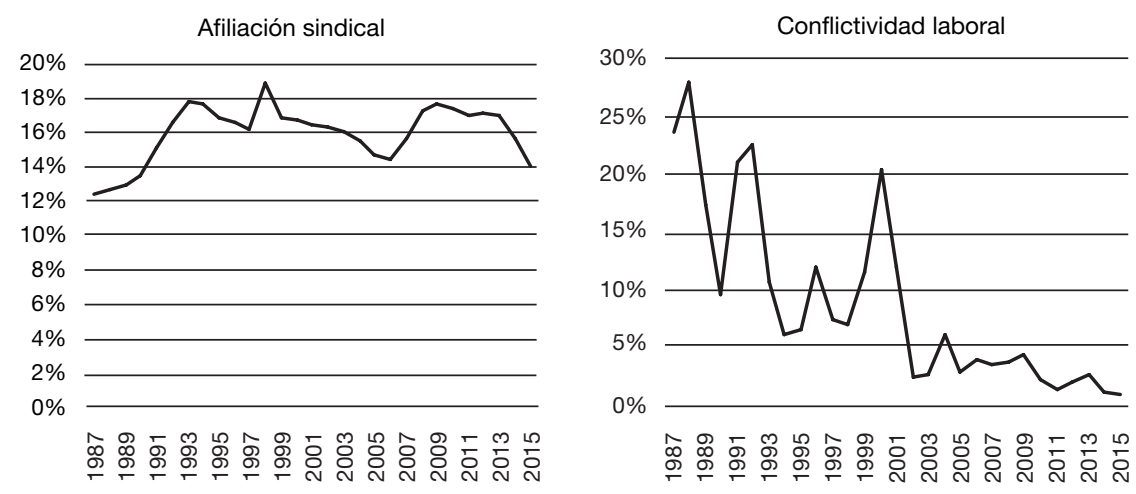

Tasa de cobertura de la negociación colectiva

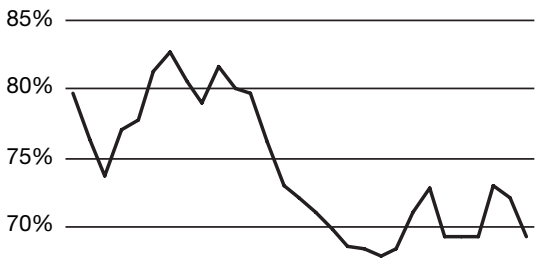

$65 \%$

$60 \%$

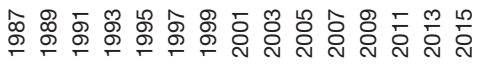

Fuentes: figura 4, OECD.STATS; figuras 5 y 6, Banco de España.

en España un suelo por debajo del que no podían caer los salarios (hasta la reforma laboral de $2010 \mathrm{y}$, sobre todo, de 2012). Además, el salario pactado en los convenios de empresa ha sido sistemáticamente inferior al pactado en los convenios de ámbito superior (es decir, la extensión y la cobertura ayudan a tener suelos salariales más elevados), y los salarios fuera de convenio han tendido a ser inferiores a los salarios acordados en convenio. Por tanto, se espera que, cuanto mayor sea la tasa de cobertura de los convenios sectoriales y nacionales, mayor sea la cuota salarial.

Variables de mercado de trabajo (figuras 7-10): tienen que ver con la estructura y las condiciones del empleo, esto es, la incidencia del empleo atípico, la protección frente al despido y la cobertura de las prestaciones por desempleo.

d) Tasa de temporalidad y

e) Tasa de parcialidad involuntaria: ambas formas de empleo atípico restan capacidad negociadora a los trabajadores por varias razones: (i) son formas de empleo que o no se incluyen en la negociación colectiva o que aparecen 
únicamente de forma periférica. Esto provoca que (ii) los incentivos de los trabajadores afectados por estas modalidades de contratación para afiliarse a un sindicato sean menores, lo que reduce su base social (Hyman, 2001), a la vez que (iii) los sindicatos tiendan a actuar en favor de la que es su base social más amplia (los trabajadores con contratos indefinidos a tiempo completo) y, en ocasiones, a externalizar los costes de los ajustes salariales sobre segmentos secundarios del mercado laboral (Rueda, 2014); (iv) esta fractura entre asalariados se reproduce en el interior de las empresas y deteriora su capacidad negociadora. Además, (v) son contratos que gozan de menor protección frente al despido y menores prestaciones tras el mismo, por lo que los trabajadores tienen menor capacidad de movilización (participación en huelgas) y de proteger sus salarios o reivindicar que incrementen (Alós y Jódar, 2005). Por lo tanto, se espera que, a mayor proporción de empleo atípico, menor será el crecimiento salarial.

f) Protección del empleo: las facilidades al despido individual o colectivo son un factor que debilita la capacidad negociadora de los trabajadores. La existencia de mayor (menor) número de barreras institucionales a la posibilidad de despedir de los empresarios puede potenciar (deteriorar) la capacidad de los empleados de reivindicar mayor (menor) salario o de proteger el que ya tienen. Para captar esto, empleamos el índice de protección del empleo elaborado por la OCDE, aplicado a las facilidades a los despidos individuales y colectivos.

g) Tasa de cobertura del desempleo: ${ }^{4}$ esta variable mide la proporción de personas desempleadas que recibe prestación por desempleo. Tiene dos efectos diferenciados sobre la participación salarial. El primero es aumentar el salario de reserva, ya que las personas desempleadas tendrán menos incentivos para aceptar empleos cuya remuneración esté por debajo de su prestación por desempleo, lo que presiona al alza la cuota salarial. El segundo efecto tiene que ver con los rasgos del sistema de prestaciones por desempleo español. La duración máxima de la prestación es de dos años, por lo que, en períodos de crisis económica, esta variable tiende aumentar su valor durante los primeros dos años para luego decrecer aceleradamente, mientras que en los períodos de crecimiento económico tiende a crecer de forma continuada, porque el desempleo tiene una menor duración media y, por tanto, una menor proporción de personas agota el tiempo que dura su prestación. En España, se espera que este segundo efecto compense al anterior y el comportamiento de la tasa de cobertura del desempleo se corresponda con el comportamiento contrario de la participación salarial. Es decir, cuando la proporción de salarios sobre la renta disminuye, la cobertura del desempleo aumenta, porque cuando

4. Aunque es un supuesto habitual en la literatura considerar la tasa de desempleo como una variable que determina la evolución salarial, su relación con la distribución de la renta no es directa, sino que se encuentra mediada por los indicadores que se han incluido en el ICN $y$, por tanto, es mejor no incluirla como variable explicativa. 
Figura 7-10. Variables de estructura y condiciones de empleo

Tasa de parcialidad involuntaria

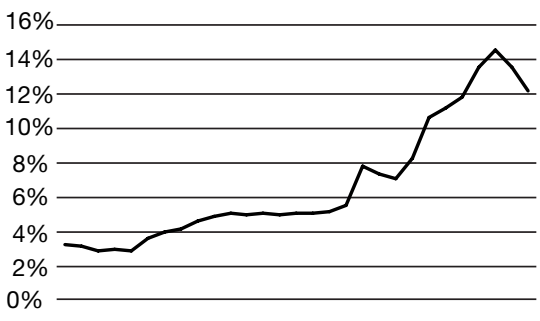

이 ๙

Tasa de cobertura desempleo

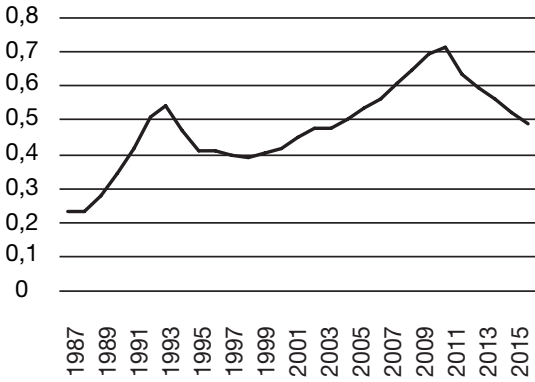

Tasa de temporalidad

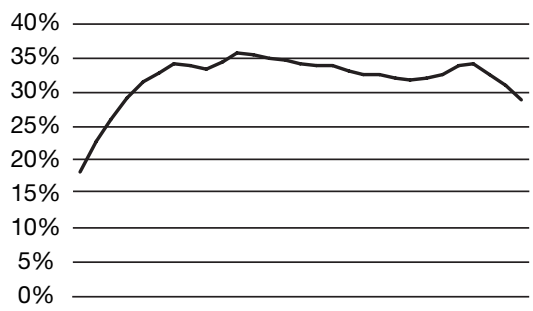

이 ๘ Índice de protección del empleo

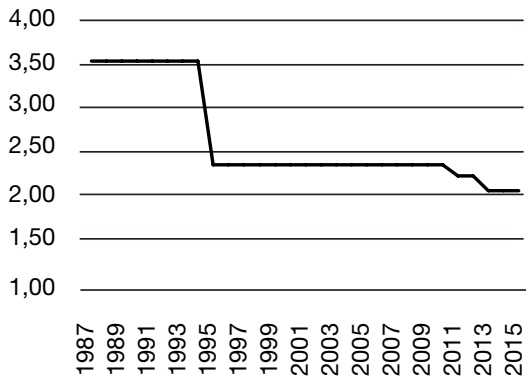

Nota: la parcialidad involuntaria se mide como la proporción de trabajadores a tiempo parcial involuntarios como porcentaje de la fuerza de trabajo.

Fuente: figuras 7 y 8, EPA; figura 9, Estadística de Prestaciones por Desempleo; figura 10, OECD.STATS.

hay crecimiento económico (basado en sectores de baja productividad) el desempleo es de menor duración.

El índice se calcula estandarizando los valores de cada una de las siete variables expuestas transformándolos en base 100 (siendo 100 el valor máximo de cada serie). Las variables que restan capacidad negociadora a los trabajadores (tasa de cobertura, tasa de desempleo, tasa de temporalidad y tasa de parcialidad involuntaria) se han incluido a través de su inversa.

A continuación, hemos aplicado la metodología de "equal weighting», de acuerdo con la terminología de OECD (2008), la cual consiste en asignar un factor de ponderación idéntico a cada variable para evitar cualquier discrecionalidad. Al igual que con los valores de las variables que han sido previamente normalizados por el valor máximo de cada serie, el índice compuesto también oscila entre 0 y 100 (siendo este su valor máximo). Aunque es sencillo, este método presenta como gran ventaja que no requiere de un gran volumen de datos (la muestra consta de 29 años) para ajustar los pesos en función de criterios estadísticos, y no presenta ningún sesgo de endogeneidad o autocorrelación a la hora de establecer los factores de ponderación. Un ejercicio similar es reali- 
Figura 11. Evolución del ICN y la participación salarial (1987-2015)

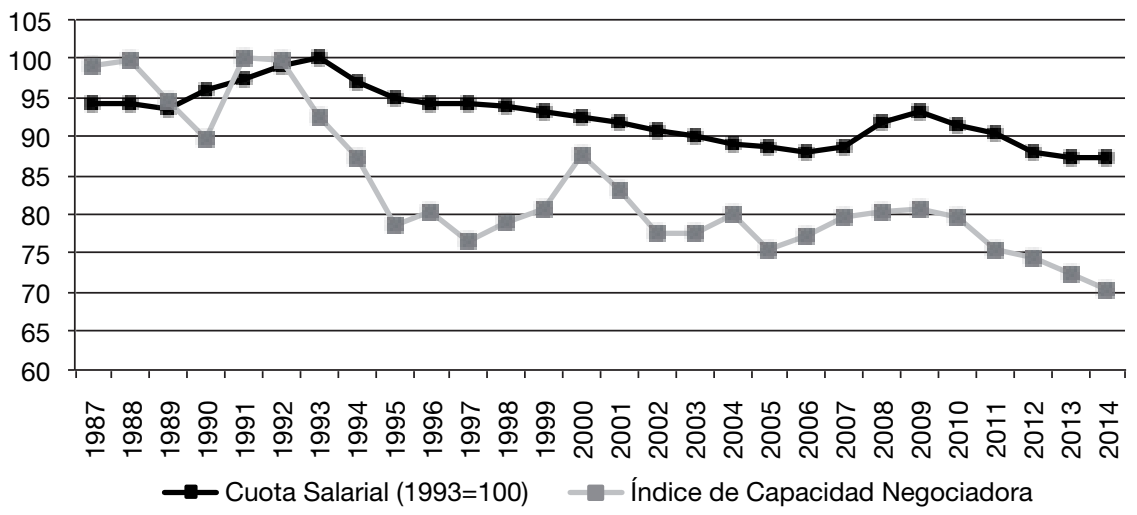

Fuente: elaboración propia con datos de Contabilidad Nacional, Banco de España, OECD.STATS, EPA y Estadística de Prestaciones por Desempleo.

zado en Eurofound (2018) para indicadores de relaciones laborales en Europa. La figura 11 muestra la evolución del ICN y de la distribución de la renta.

El ICN presenta una caída tendencial a lo largo del período, y el comportamiento de sus componentes recoge lo expuesto en la sección 3 (figura 12). En primer lugar, se constata que la modalidad de expansión del empleo en España se ha dado sobre la segmentación laboral y el empleo atípico, cuya evolución supone un deterioro constante del poder negociador. Asimismo, también se comprueba que el proceso de desregulación del mercado de trabajo se concentró en tres momentos: las reformas laborales de 1994, 2010 y 2012 (el efecto de todas ellas se refleja en el siguiente año), cuyas principales medidas se han enumerado en la sección 3.2. No obstante, cabe destacar el importante peso que tuvo la caída de la protección al empleo por la reforma de 1994, que, recordemos, fue mediante la cual se introdujeron las empresas de trabajo temporal (ETT) y se añadieron como causas del despido objetivo las organizativas y de producción, así como una mayor flexibilidad en su aplicación.

Por otro lado, la participación en huelgas es el elemento más volátil del ICN (los momentos de gran conflicto social son seguidos necesariamente de situaciones de menor movilización, por lo que la variación de la variable es negativa). No obstante, en la figura se aprecia una primera etapa de gran movilización, con las huelgas generales del 14D-1988, el 28M-1992 y el 27E1994 (que resultó poco exitosa con relación a los años anteriores, a pesar de la crisis y de la reforma laboral aprobada), y con fuertes repuntes en los años 1991 y 1996, que reflejan respectivamente las huelgas del sector público y el transporte aéreo, y de nuevo de los funcionarios. Estos mismos sectores fueron responsables del repunte de 1999 y 2000.

A partir de entonces, la movilización disminuye notablemente y las siguientes huelgas generales no supusieron empujes importantes a la capacidad 
Figura 12. Contribuciones al crecimiento del ICN (tasas de variación, 1988-2015)

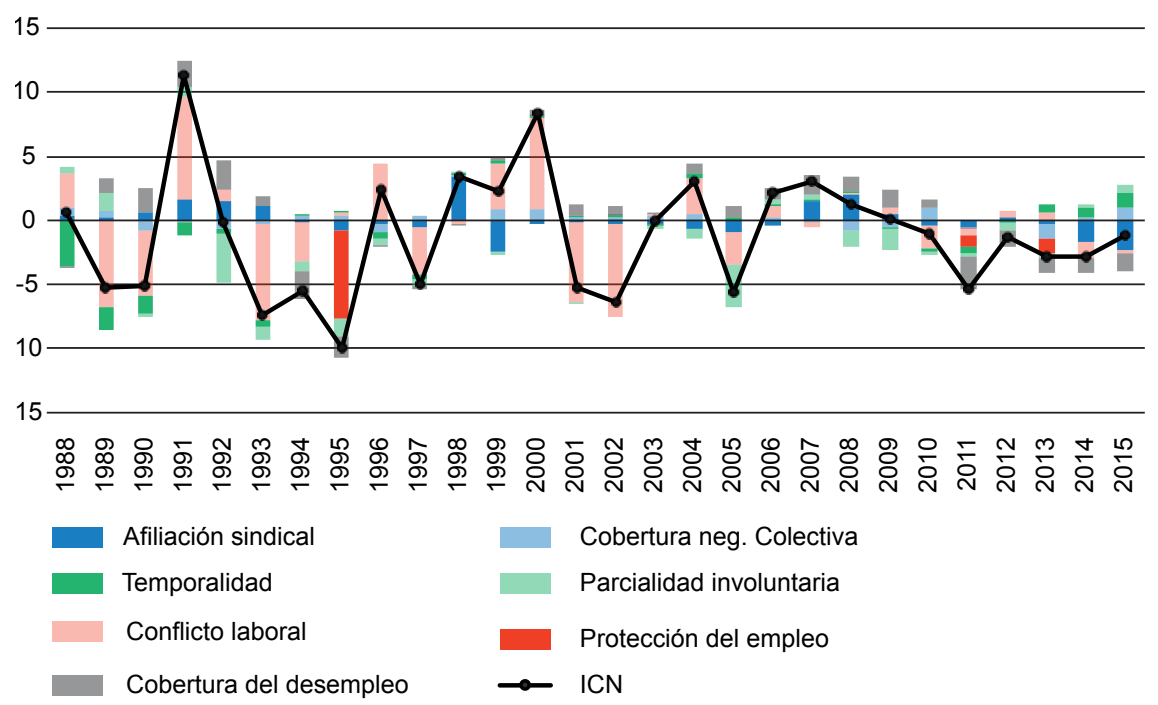

Fuente: elaboración propia con la metodología comentada en el texto.

negociadora. Es interesante comparar esta variable con la tasa de afiliación sindical, que se mantiene considerablemente estable. Mientras que la capacidad de los sindicatos de impulsar el conflicto social disminuye mucho, la afiliación lo hace mucho menos. Dicho de otro modo, lo que verdaderamente supone un deterioro del poder negociador es el grado de aceptación de los objetivos sindicales por el conjunto de trabajadores y no la cantidad de afiliados.

Por último, merece la pena señalar cómo la tasa de cobertura del desempleo supone un estabilizador del poder negociador durante los dos primeros años de las crisis, que es el máximo de duración de la prestación por desempleo. La cobertura de la negociación colectiva experimenta poca variación y su contribución al crecimiento del ICN es muy baja.

\section{Relación entre el ICN y la cuota salarial}

A pesar de la evidencia cualitativa y cuantitativa señalada sobre el resultado de la pugna distributiva, el contraste estadístico de la hipótesis se enfrenta a ciertas restricciones derivadas de la cantidad y la calidad de los datos disponibles. La elaboración del ICN permite eludir en parte estos obstáculos, entre los que el más severo es la restricción temporal, ya que solo existen series para el período $1987-2015$ y con una frecuencia anual.

La correlación entre el índice de capacidad negociadora y la participación salarial se muestra en la figura 13 , donde se comprueba el alto grado de asociación existente entre ambas variables (un $56 \%$ de la varianza de la cuota salarial 
Figura 13. Relación entre el ICN y la cuota salarial (1987-2015)

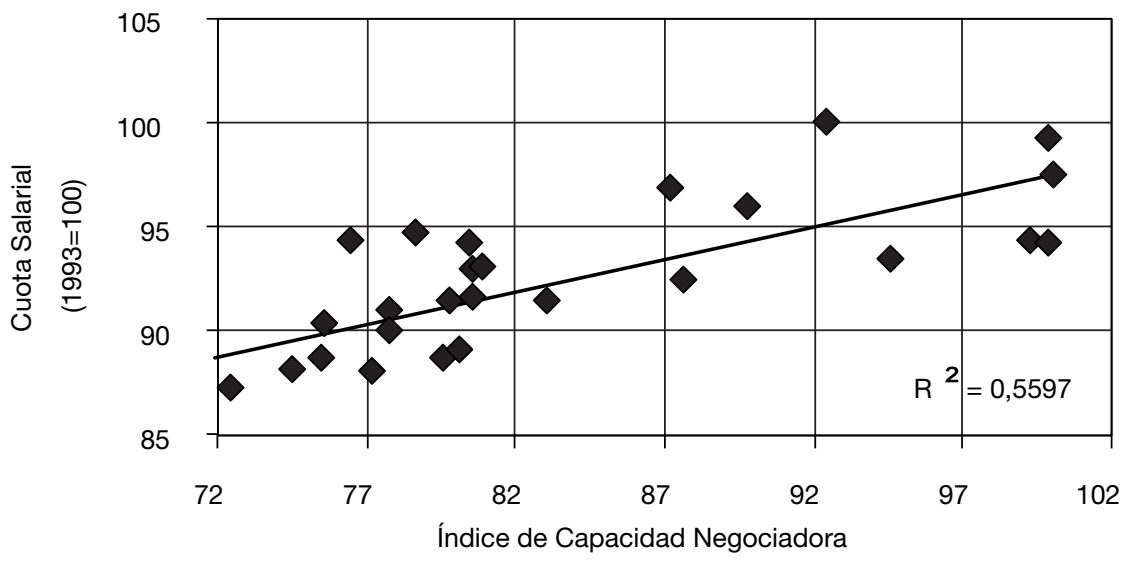

Fuente: elaboración propia con la metodología comentada en el texto.

puede explicarse por el ICN). Asimismo, si se considera que el ICN es un indicador adelantado y que opera con un año de retraso sobre la distribución de la renta (y eliminando un valor atípico), el porcentaje explicado aumenta hasta el $74 \%$.

Cabe señalar que el ICN capta la dinámica, por lo que lo importante es su evolución en el tiempo, ya que lo que pretendemos explicar es el movimiento de la participación salarial de la economía española y no su valor bruto.

Sin embargo, lo anterior no aporta suficiente información sobre si realmente el ICN ayuda a explicar la evolución de la cuota salarial. Para ello estimamos una serie de modelos dinámicos mediante regresión lineal. ${ }^{5}$ En el primero, incluimos como variable dependiente la cuota laboral (W/Y) y como variable explicativa el ICN y la variable dependiente retardada un período (ya que se ha encontrado un AR1 en los residuos de la ecuación cuando esta variable no se incluye).

Los resultados se muestran en la tabla 1 . Todos los modelos se encuentran validados al superarse los test habituales de normalidad, ausencia de autocorrelación y heterocedasticidad. Como se observa en el modelo 1, el signo de la variable explicativa es el esperado, con una relación positiva entre la evolución de la cuota laboral y el ICN. De tal forma, un incremento (reducción) del ICN se transmite a un incremento (reducción) de la cuota laboral. El otro aspecto relevante es que el elemento autorregresivo, aunque elevado $(0,8)$, no se encuentra próximo a la unidad, lo que indicaría presencia de raíz unitaria.

5. Por brevedad, no se muestran los resultados de test de diagnóstico de los modelos, pero todos se encuentran validados al ser los residuos ruido blanco y superar los test habituales de estacionalidad, homocedasticidad, normalidad y ausencia de autocorrelación. Los resultados están disponibles a petición a los autores. 
Tabla 1. Modelos dinámicos de estimación lineal

\begin{tabular}{|c|c|c|c|c|c|c|c|c|}
\hline \multirow{2}{*}{$\frac{\text { Dep. W/Y }}{\text { Constante }}$} & \multicolumn{2}{|c|}{ Modelo 1} & \multicolumn{2}{|c|}{ Modelo 2} & \multicolumn{2}{|c|}{ Modelo 3} & \multicolumn{2}{|c|}{ Modelo 4} \\
\hline & 5,88 & $(3,94)$ & 6,58 & $(4,66)$ & 6,83 & $(5,46)$ & 5,50 & $(3,99)$ \\
\hline ICN & $0,07^{\star \star}$ & $(0,02)$ & $0,06^{\star}$ & $(0,02)$ & $0,06^{\prime}$ & $(0,03)$ & $0,07^{\star \star}$ & $(0,02)$ \\
\hline Peso de la industria & & & 0,00 & $(0,02)$ & & & & \\
\hline $\mathrm{K} / \mathrm{L}$ & & & & & $-0,00$ & $(0,02)$ & & \\
\hline Gobierno & & & & & & & 0,25 & $(0,30)$ \\
\hline $\mathrm{AR}(1)$ & $0,80^{\star \star \star}$ & $(0,08)$ & $0,79^{* \star *}$ & $(0,10)$ & $0,80^{\star \star *}$ & $(0,09)$ & $0,80^{\star \star *}$ & $(0,08)$ \\
\hline Dummy2008 & $1,80^{*}$ & $(0,72)$ & $1,82^{\star}$ & $(0,74)$ & $1,80^{*}$ & $(0,74)$ & $1,90^{\star}$ & $(0,74)$ \\
\hline adj. R-squared & 0,91 & & 0,91 & & 0,90 & & 0,91 & \\
\hline JB test (p-value) & 0,69 & & 0,63 & & 0,63 & & 0,62 & \\
\hline Box-Pierce (p-value) & 0,71 & & 0,71 & & 0,69 & & 0,86 & \\
\hline Breusch-Pagan ( $p$-value) & 0,22 & & 0,19 & & 0,27 & & 0,17 & \\
\hline $\mathrm{N}$ & 28 & & 28 & & 28 & & 28 & \\
\hline $\mathrm{BIC}$ & 70,54 & & 73,77 & & 73,80 & & 73,08 & \\
\hline
\end{tabular}

Notas: se obtienen los mismos resultados incluyendo un retardo en el ICN. Desviaciones típicas entre paréntesis. '***' indica un p-valor menor que 0,001 , '**' menor que 0,01 , '*' menor que $0,05 \mathrm{y}$ ' ' menor que 0,1 . Fuente: elaboración propia con la metodología comentada en el texto.

Como cabía esperar este primer modelo presenta un criterio de información bayesiana menor (lo que indica que es el mejor ajuste de los realizados). Además, se han observado datos atípicos que podían sesgar los resultados, por ello se ha añadido una variable dummy para el año 2008 (toman valor uno en ese año), que refleja que la cuota laboral fue mayor de lo esperado por el modelo (esto se debe, lógicamente, al mencionado efecto de composición del empleo derivado de la crisis económica).

En el modelo 2 hemos incluido como variables explicativas el ICN y la proporción del número de trabajadores del sector industrial sobre el conjunto de trabajadores, que es la medida habitualmente utilizada en la literatura para reflejar el efecto de la desindustrialización. Mientras que el ICN vuelve a mostrar el signo esperado y significativo, el peso de la industria no es significativo y su coeficiente es nulo (las variables han sido normalizadas respecto a su valor máximo para facilitar la comparación de los efectos).

A continuación, probamos un tercer modelo que incorpora la relación entre el stock de capital y el número de empleados (K/L). De nuevo, esta variable adicional no es significativa. Por último, en el modelo 4 incluimos el papel de los distintos gobiernos siguiendo la propuesta de Kristal (2010), según la cual la cuota salarial tiende a crecer cuando gobiernan partidos socialdemócratas. Esta variable (Gobierno) toma valor 1 durante los gobiernos del Partido Popular y valor 0 para los del PSOE. En este caso, los resultados tampoco son significativos.

Por tanto, es posible afirmar que ni la desindustrialización, ni el incremento de la capitalización por empleado (que reflejaría el efecto tecnológico), ni el cambio de gobierno aportan información relevante sobre la evolución de la distribución de la renta una vez que se ha considerado el ICN. En otras palabras, 
el ICN es capaz de capturar todos esos efectos a partir de las variables consideradas en su elaboración y no requiere de ninguna variable explicativa adicional. Es decir, los posibles efectos que hayan podido tener la desindustrialización, el auge de la mecanización y el color político de los gobiernos ya se encuentran incluidos en el propio índice. Todo esto nos permite afirmar que la evolución del ICN explica la mayor parte del cambio distributivo.

\section{Conclusiones}

Este trabajo tenía por objetivo explicar el comportamiento de la distribución funcional de la renta en la economía española, que se ha decantado en contra de las rentas del trabajo a lo largo de los años 1987-2015. Nuestro punto de vista destaca como factor determinante de este comportamiento la capacidad de negociación de los trabajadores, que viene conformada por un conjunto de variables de corte socioinstitucional relacionadas con los ámbitos de la estructura y condiciones de empleo y las relaciones laborales.

Esta complejidad ha sido recogida en un índice de capacidad negociadora. El ICN es un instrumento que permite, en primer lugar, describir estadísticamente la evolución de la fortaleza de los trabajadores a la hora de determinar sus salarios. Durante el período de estudio, la capacidad negociadora se ha visto reducida por los profundos cambios acaecidos en el mercado de trabajo y el marco de relaciones laborales, que han favorecido la expansión del empleo atípico, lo que ha debilitado la protección de los trabajadores frente a los despidos e impulsado la moderación salarial en los acuerdos colectivos. El efecto de estas variables no pudo ser compensado por el nivel de conflicto laboral, que, aunque elevado, sufrió una caída tendencial y fue comparativamente bajo durante la última crisis económica. Todas estas tendencias quedan registradas en nuestro indicador.

En segundo lugar, hemos comprobado que el ICN tiene capacidad de explicar estadísticamente el movimiento de la cuota salarial y puede ser un instrumento relevante para la investigación sobre distribución de la renta. En nuestro análisis se observa una alta correlación entre ambas variables.

Además, se ha estimado un modelo dinámico que muestra el peso que ha tenido la caída del ICN en la reducción de la cuota laboral, así como el papel de las habituales variables de control, donde la desindustrialización es la única variable que ha sido estadísticamente significativa.

Colateralmente, se han mostrado las ventajas de esta metodología. La primera es que el ICN permite cuantificar distintos factores cualitativos, así como darles un peso no discrecional. La segunda se refiere a que la mayoría de estos indicadores se elaboran con periodicidad anual $y$, al agruparlos mediante un índice, la regresión ajusta mejor y se evitan problemas de colinealidad y de falta de grados de libertad. Finalmente, hay que destacar que se trata de una metodología estandarizable y replicable, que no ha sido utilizada hasta la fecha y que puede ser empleada con datos de otros países para comprobar la robustez de los resultados obtenidos. Si se dispone de una muestra más amplia, 
se podrán utilizar métodos de ponderación estadísticos que complementarán al «equal weighting» aquí utilizado.

En conclusión, gracias a la metodología desarrollada, podemos afirmar que existe una relación causal entre la pérdida de capacidad negociadora, dependiente de factores socioinstitucionales, y el deterioro de la participación salarial. En ese sentido, la evidencia aquí aportada, aunque sujeta a futuros desarrollos, supone una oportunidad para profundizar en el fenómeno del cambio distributivo en línea con las últimas investigaciones.

\section{Agradecimientos y financiación recibida}

Los autores desean agradecer a Nacho Álvarez, Rafael Fernández, Julián López Gallego, Enrique Palazuelos y Adrián Rial los comentarios y sugerencias realizados a versiones preliminares de este artículo.

Daniel Herrero agradece el apoyo económico recibido por las becas de Personal Investigador en Formación financiadas por la Universidad Complutense de Madrid y el Banco Santander (CT17/17-CT18/17).

\section{Referencias bibliográficas}

Acemoglu, D. (2003). «Labor- and Capital-Augmenting Technical Change». Journal of European Economic Association, 1 (1), 1-37. <https://doi.org/10.1162/154247603322256756>

Aidt, T. S. y Tzannatos, Z. (2008). «Trade unions, collective bargaining and macroeconomic performance: a review». Industrial Relations Journal, 39 (4), 258-295. $<$ https://doi.org/10.1111/j.1468-2338.2008.00488.x>

Alonso, L. E. y Fernández-Rodríguez, C. (eds.) (2012). La financiarización de las relaciones salariales. Madrid: Catarata.

Alós, R. y Jódar, P. (2005). «Relaciones laborales segmentadas en mercados de trabajo segmentados: algunas repercusiones en la calidad de vida laboral y en la participación sindical». Gaceta Sindical: Reflexión y Debate (5), 223-250.

Astudillo, J. (2004). «La trampa partidista de la UGT: de la relación solidaria con el PSOE a la unidad de acción sindical con CC. OO.». Revista Española de Ciencia Politica (11), 73-101. <https://recyt.fecyt.es/index.php/recp/article/view/37357>.

Autor, D. (2015). «Why are there still so many jobs? The history and future of workplace automation». Journal of Economic Perspectives, 29 (3), 3-30. <http://dx.doi.org/10.1257/jep.29.3.3>

Beneyto, P. (2016). «Trabajo y sindicalismo en la globalización». Revista Española de Sociología (RES) (25), 61-87. $<$ https://recyt.fecyt.es/index.php/res/article/view/65406>.

Bengtsonn, E. (2014). «Do unions redistribute income from capital to labour? Union density and labour's share since 1960». Industrial Relations Journal, 45 (5), 389-408. <https://doi.org/10.1111/irj.12065>

BLANCO, J. (2005). «El sindicalismo español frente a las nuevas estrategias empresariales de trabajo y empleo». Cuadernos de Relaciones Laborales, 22 (2), 93-115. <https://revistas.ucm.es/index.php/CRLA/article/view/CRLA0404220093A>. 
Calmfors, L. y Driffill, J. (1988). «Bargaining Structure, Corporatism and Macroeconomic Performance». Economic Policy, 3 (6), 13-61. $<$ https://doi.org/10.2307/1344503>

CARD, D. y DiNardo, J. (2002). «Skill-biased technological change and rising wage inequality: some problems and puzzles». Journal of Labor Economics, 20 (4), 73383. <https://doi.org/10.1086/342055>

Cárdenas del Rey, L. y Herrero Alba, D. (2018). «Determinantes socio-institucionales de la distribución de la renta. El caso de España (1987-2015)». Instituto Complutense de Estudios Internacionales (ICEI), WP03/18. <https://www.ucm. es/data/cont/media/www/pag-106415/WP0318/WP0318.pdf>.

Casas, M. E. (2014). "Reforma de la negociación colectiva en España y sistema de Relaciones Laborales». Cuadernos de Relaciones Laborales, 32 (2), 275-309. <https://doi.org/10.5209/rev_CRLA.2014.v32.n2.46766>

CES (2013). «Distribución de la renta en España: desigualdad, cambios estructurales y ciclos». Informe del Consejo Económico y Social España, núm. 03/2013.

Clayton, R. y Pontusson, J. (1998). «Welfare-State Retrenchment Revisited: Entitlement Cuts, Public Sector Restructuring, and Inegalitarian Trends in Advanced Capitalist Societies». World Politics, 51 (1), 67-98. <https://doi.org/10.1017/S0043887100007796>

Cuadrado, J. R. y Maroto, A. (2012). El problema de la productividad en España: causas estructurales, cíclicas y sectoriales. Madrid: Fundación de las Cajas de Ahorros (FUNCAS).

Dünhaupt, P. (2016). «Determinants of labour's income share in the era of financialisation». Cambridge Journal of Economics, 41 (1), 283-306. <https://doi.org/10.1093/cje/bew023>

Etxezarreta, M. (1991). La reestructuración del capitalismo en España, 1970-1990. Madrid: Icaria Editorial.

Eurofound (2018). Measuring varieties of industrial relations in Europe: A quantitative analysis. Luxemburgo: Publications Office of the European Union.

Fernández, C. J.; Ibáñez, R. y Martínez, M. (2016). "Austerity and collective bargaining in Spain: The political and dysfunctional nature of neoliberal deregulation». European Journal of Industrial Relations, 22 (3), 267-280. <https://doi.org/10.1177/0959680116643433>

García-Calavia, M. A. (2001). «El sindicalismo tras la reestructuración productiva». Papers. Revista de Sociologia (65), 11-30. <https://doi.org/10.5565/rev/papers/v65n0.1704>

García-Nogueroles, J. M. (2010). «Transformaciones en el empleo, transformaciones en el tejido social. Las nuevas clases trabajadoras de servicios». Papers. Revista de Sociologia, 95 (1). <https://doi.org/10.5565/rev/papers/v95n1.670>

García-Serrano, C. y Malo, M. A. (2013). «Beyond the contract type segmentation in Spain». Employment Working Paper (143). Ginebra: International Labor Organization.

González, S. y Luque, D. (2015). «Crisis económica y deterioro de los pactos sociales en el sur de Europa. Los casos de España y Portugal». Revista Internacional de Sociología, 73 (2), 1-13. <https://doi.org/10.3989/ris.2014.03.17>

Hibbs, D. (1987). The American Political Economy. Cambridge: Harvard. 
Hyman, R. (2001). Understanding European Unionism. Between Market, Classes and Society. Londres: SAGE Publications.

Jayadev, A. (2007). "Capital account openness and the labour share of income». Cambridge Journal of Economics, 31 (3), 423-43. <https://doi.org/10.1093/cje/bel037>

Joint Research Centre, European Commission y OECD (2008). Handbook on constructing composite indicators: methodology and user guide. OECD Publishing.

Kenworthy, L. (2001). «Wage-Setting Institutions: A Survey and Assessment». World Politics, 54 (1), 57-98. <https://doi.org/10.1353/wp.2001.0023>

Kristal, T. (2010). «Good times, bad times: postwar labor's share of national income in capitalist democracies». American Sociological Review, 75 (5), 729-763. <https://doi.org/10.1177/0003122410382640>

Lavoie, M. y Stockhammer, E. (2013). Wage-led Growth: An Equitable Strategy for Economic Recovery. Londres: Palgrave MacMillan and International Labour Organization.

López, P. (1996). «La construcción de una tipología de segmentación del mercado de trabajo». Papers. Revista de Sociologia (48), 41-58. $<$ https://doi.org/10.5565/rev/papers.1812>

López, P.; Miguélez, F.; Lope, A. y Coller, X. (1998). «La segmentación laboral: hacia una tipología del ámbito productivo». Papers. Revista de Sociologia (55), 45-77. <https://doi.org/10.5565/rev/papers.1932>

Luque, D. (2012). «Huelgas e intercambio político en España». Revista Internacional de Sociología, 70 (3), 561-585. <https://doi.org/10.3989/ris.2011.02.25>

Molina, O. (2014). «Beyond de-centralization: The erosion of collective bargaining in Spain during the Great Recession». Stato e Mercato, 34 (3), 397-422.

OCDE (1997). Employment Outlook 1997. Low-wage jobs: stepping stones to a better future or traps? París.

- (2004). Employment Outlook 2004. París.

- (2008). Handbook on constructing composite indicators methodology and user guide. Organización para la Cooperación y el Desarrollo Económicos (OCDE) y Joint Research Centre, Comisión Europea.

Orson, M. (1982). The Rise and Decline of Nations: Economic Growth, Stagflation, and Social Rigidities. Yale: Yale University Press.

OnARAN, O. (2011). "Globalisation, macroeconomic performance and distribution». En: Hein, E. y Stockhammer, E. (eds.). A Modern Guide To Keynesian Macroeconomics and Economic Policies. Cheltenham: Edward Elgar, 240-66.

PÉrez-Ortiz, L. (2004): La influencia de la negociación colectiva en los resultados macroeconómicos en la Unión Europea. Tesis doctoral. Madrid: Universidad Autónoma de Madrid (UAM).

Polavieja, J. (2005). "Desregulación parcial y desigualdad horizontal en España». Revista Internacional de Sociología, 63 (41), 9-36. <https://doi.org/10.3989/ris.2005.i41.211>

Portella-Carbó, F. (2017). «El paro de masas en España (1959-2014): la estructura productiva en la integración al capitalismo global». Revista de Historia Industrial, 67, $125-167$. <https://doi.org/10.1344/rhi.v26i67.18191> 
Rodrick, D. (1997). Has Globalization Gone Too Far? Washington, DC: Institute of International Economics.

Rubin, B. A. (1986). "Class Struggle American Style: Unions, Strikes and Wages». American Sociological Review, 51 (5), 618-633. $<$ https://doi.org/10.2307/2095488>

Rueda, D. (2014). «Dualization, crisis and the welfare state». Socio-Economic Review, 12 (2), 381-407. <https://doi.org/10.1093/ser/mwu015>

SÁnchez-Mosquera, M. (2013). «De los acuerdos generales de renta a la concentración social competitiva europea. El caso español, 1977-2012». Trabajo: Revista Andaluza de Relaciones Laborales (28), 119-140. <https://doi.org/10.33776/trabajo.v0i28.2245>

Schor, J. B. y Bowles, S. (1987). «Employment rents and the incidence of strikes». The Review of Economics and Statistics, 69 (4), 584-592. $<$ https://doi.org/10.2307/1935952>

Sola, J.; Alonso, L. E.; Fernández, C. J. y Ibáñez, R. (2013). «The expansion of temporary employment in Spain (1984-2010): neither socially fair nor economically productive». En: Koch y Fritz (ed.). Non-Standard Employment in Europe. Londres: Palgrave Macmillan, 67-83.

Stocкнамmer, E. (2004). «Financialization and the slowdown of accumulation». Cambridge Journal of Economics, 28 (5), 719-41. <https://doi.org/10.4337/9781845421717.00010>

- (2017). «Determinants of the wage share: A panel analysis of advanced and developing economies». British Journal of Industrial Relations, 55 (1), 3-33. <https://doi.org/10.1111/bjir.12165>

Toharia, L. (2003). «El mercado de trabajo en España, 1978-2003». Información Comercial Española, ICE Revista de Economía (811), 203-220.

Torrejón, S. (2019). «Los cambios en la estructura del empleo en España a lo largo del ciclo económico: patrones de cambio y factores explicativos (1995-2014)». Papers. Revista de Sociologia, 104 (4), 605-633. $<$ https://doi.org/10.5565/rev/papers.2567>

Visser, J. (2015). «Codebook of the ICTWSS. Data base, version 5.0». Amsterdam Institute for Advanced Labour Studies AIAS.

- (2016). "What happened to collective bargaining during the great recession?». IZA Journal of Labor Policy, 5 (9), 1-35. <https://doi.org/10.1186/s40173-016-0061-1>

Wallerstein, M. (1999). «Wage-Setting Institutions and Pay Inequality in Advanced Industrial Societies». American Journal of Political Science, 43 (3), 649-680. $<$ https://doi.org/10.2307/2991830>

Wright, E. O. (2000). «Working Class Power, Capital Interest, and Class Compromise». American Journal of Sociology, 105 (4), 957-1.002. <https://doi.org/10.1086/210397> 